\title{
Biochemical Changes in Haemolymph of Fresh Water Crab, Paratelphusa jacquemontii (Rathbun) Exposed to Copper
}

\author{
*A.Maharajan, K.Shanmugavel, P.S.Parurukmani \\ PG \& Research Department of Zoology, Khadir Mohideen College, \\ Adirampattinam-614701, Thanjavur Dist, Tamil Nadu, India \\ E.mail: athimaha@yahoo.co.in
}

\begin{abstract}
Paratelphusa jacquemontii, a fresh water crab are abundantly found in the Orathanadu region, Thanjavur district of Tamil Nadu State, mainly in and around paddy fields. They were brought to the laboratory from their natural habitat, and first subjected to acclimatization to the laboratory conditions. They were subsequently exposed to sublethal concentrations of $1 / 10^{\text {th }} \& 1 / 20^{\text {th }}$ of $\mathrm{LC}_{50}$ value for $96 \mathrm{hrs}$ copper and the haemolymph total protein, free sugar and lipid level of the animal were estimated to study the stress caused by this heavy metal toxicant. In the present study, total protein, free sugar and lipid level of the animal showed a gradual declining trend from 0 to 15 days in the experimental animals exposed to copper.
\end{abstract}

Keywords: Copper, Haemolymph, Biochemistry, Paratelphusa jacquemontii.

\section{Introduction}

Environmental poisoning of water by heavy metals has increased in recent years due to extensive use of heavy metals in agriculture, and chemical and industrial processes, posing a serious threat to living organisms. Among the heavy metals, copper, chromium, and iron being major pollutants from industrial effluents and agricultural waste in aquatic environment, cause maximum effects on non-target aquatic organisms resulting in imbalance of the ecosystem. The effect of heavy metals on aquatic organisms is currently attracting widespread attention, particularly in studies related to industrial pollution. Heavy metals are introduced 
into aqueous environment through industrial and urban effluents, soil leaching, and rainfall. Fishes occupy high tropic level in accumulating various xenobiotics in the aquatic environment. Several investigations have already shown that metals accumulate at higher concentrations in freshwater and marine food chain. The waste water from textile, dyeing, and printing industries, tannery etc. are highly coloured and can cause an imbalance in the ecological system. Today heavy metals in aquatic ecosystems often show levels above the accepted levels. Extensive use of various chemical contaminants is known to adversely affect the growth of various organisms. The toxicity of such chemical constituents in invertebrates is mainly reflected on the central nervous system. It is further known to influence other physiological processes, including respiration. Respiration is obviously the most vital of all functions, and serves as an index of all biochemical changes that occur due to the effect of toxicants on the overall metabolism of exposed animals. Any change in the oxygen consumption due to pollution stress creates a physiological imbalance in the organisms.

In biological systems, the biocatalysts play a vital role in the metabolic pathways. Animal exposed to stress conditions alter their physiological status with the help of enzymes. Toxicants like pesticides are known to secrete hyper or hypo level of enzymes. The trace metal concentrations in Queensland Estuarine crabs, Australoplax tridentate have been observed [1]. When any aquatic animal is exposed to polluted medium, a sudden stress is developed for which the animals should meet more energy demand to overcome the toxic stress. Verma et al.[2] reported on the toxic effects of sublethal concentration of copper sulphate, on certain biologically important enzymes in Saccobranchus fossilis.

The neurosecretory structure in the eyestalk is the most important component of the neuroendocrine system of stalk-eyed crustaceans, and is mainly controlled by the $\mathrm{cHH}$ synthesized within X-organ [3], and released from the sinus gland (SG) complex in the eyestalk [4]. The effect of heavy metals on blood glucose levels in Palaemon elegans showed that the intermediate sublethal concentrations of $\mathrm{Hg}$, $\mathrm{Cd}, \mathrm{Cu}$, and $\mathrm{Pb}$ produce significant hyperglycaemic responses, while high concentrations elicit no hyperglycaemia in 24 hours. In contrast, animals exposed to $\mathrm{Cu}$ and $\mathrm{Zn}$ showed hyperglycaemia even at high concentrations. These differences in response could be explained on the basis of the physiological roles these two essential elements play. In crustaceans, $\mathrm{Cu}$ acts as neuroransmitter acting on Chh neuroendrocrine cells, and consequent tolerance adaptations, as opposed to the toxic xenobiotic heavy metals $\mathrm{Cd}, \mathrm{Hg}$, and $\mathrm{Pb}$ Though there are a number of heavy metals such as copper, zinc, arsenic, cadmium, and mercury, in the present work copper alone has been studied as a toxicant. Copper may act as a toxicant in the form of sulfate or phosphate, or any other form. Actually, copper is one of the most important elements used in melanin pigments, protein synthesis, and blood protein synthesis. It is also helpful in the formation of blood, and many oxidative enzymes. Copper is also helpful in the formation of oxidative enzymes. Copper is used in many industries such as paint,steel, ceramic, fertilizers, etc., and mixes with water as effluent. It causes disturbances in various metabolic processes 
such as bone formation, reproduction, respiration survey of literature reveals that considerable work has been done on the effect of copper as a toxicant in marine animals, but comparatively little attention has been focused on their fresh water counterparts. Hence, the present investigation was conducted on the fresh water crab, Paratelphusa jacquemontii after exposure to copper in various concentrations.

\section{Materials and Methods}

\subsection{Test animal collection and maintenance}

Fresh water crab, Paratelphusa jacquemontii of carapace size ranging from 4$5 \mathrm{~cm}$ and weight 50-70g were collected from the paddy field of Orathanadu, Thanjavur Dist, Tamil Nadu. They were transported and kept for acclimatization in rectangular tank of 1001 capacity containing well aerated filtered fresh water maintained at ambient temperature $\left(27 \pm 2{ }^{\circ} \mathrm{C}\right)$ for a period of one week. Before stocking, the tank was washed with clean water several times. Finally, the tank was washed with $0.1 \% \mathrm{KmNO}_{4}$ for disinfection. Before introducing into the tank, the fishes were screened for any visible pathological symptoms and were treated with $0.1 \%$ of $\mathrm{KmNO}_{4}$.

\subsection{Preparation of stock solution for copper toxicity test}

$3.983 \mathrm{gm}$ of Copper sulphate was dissolved in one litre of double distilled water and used as the stock solution for preparing different concentrations of copper in rearing water. It was stored in a clean standard flask at room temperature, in the laboratory.

\subsection{Exploratory test}

Exploratory tests, otherwise called range finding test, were carried out to assess the approximate effective concentration range of copper required for conducting short term tests to assess the effect of copper on the metabolic function of the crab, as recommended by APHA [5]. The test solutions were prepared over a wide range of concentrations. These tests were performed by exposing 10 specimens of Fresh water crab, Paratelphusa jacquemontii in 10 litre fresh water containing different concentrations of copper. The dead animals were removed immediately. Death of each animals was recorded. Three replicates were made for short term toxicity tests, the least concentration was chosen where no mortality was recorded in $24 \mathrm{hrs}$ and the highest lethal concentration was where $100 \%$ mortality was recorded in $24 \mathrm{hrs}$. 


\subsection{Acute Toxicity test}

To study the toxicity of copper, the Static Bioassay Method was followed [5]. The test individuals were exposed to selected and serially diluted copper concentrations. For acute toxicity test, 10 active animals each were exposed to various concentrations of the copper $(10,20,30,40,50,60,70,80,90$ and $100 \mu \mathrm{g} / \mathrm{l})$ using fresh water as control. The manifestation time and survival time of crab were observed. Crabs were exposed to the above said concentrations along with common control. Experimental animals were starved for one week. The experiments were conducted in three replicates at room temperature. No feed was given during the test period.

\subsection{Sub lethal toxicity tests}

For sublethal toxicity tests, the crabs were grouped into three batches. Each batch had 10 animals and had 3 replicates.

Group I : Crabs were maintained in normal Fresh water and served as control.

Group II : Crabs were exposed to the sublethal concentration of $6.75 \mu \mathrm{g} / 1\left(1 / 10^{\text {th }}\right.$ of LC50 value for 96 hours) of copper in Fresh water.

Group III: Crabs were exposed to the sublethal concentration of $13.5 \mu \mathrm{g} / \mathrm{l}\left(1 / 20^{\text {th }}\right.$ of LC50 value for 96 hours) of copper in Fresh water.

The media were renewed every alternate day. Crabs were fed daily with artificial feed. Two specimens each from the groups I, II and III were sacrificed after 0,5 th 10th and 15th days of the experiment.

\subsection{Tissue samples and biochemical analysis}

Sampling was done on 0, 5, 10 and $15 \mathrm{DoE}$ and on each sampling occasion, 10 crabs from each group (two experimental and one control) were sacrificed. From each crab, The haemolymph was extracted from the thigh region of the crab with the help of a syringe, and the biochemical constituents (proteins, carbohydrates and lipids) were estimated by following standard procedures. The total protein (TP) and the total carbohydrate (TC) concentrations in haemolymph were determined according to the methods of Lowry et al. [6] and Roe [7]. The total lipid (TL) content was estimated by the method of Barnes and Blackstock [8].

\section{Results}

\subsection{Acute Toxicity Test}

Acute toxicity study was done to find out the impact of copper on Paratelphusa jacquemontii within a short period. In the present study the $96 \mathrm{hrs} \mathrm{LC}_{50}$ value was found to be $67.5 \mu \mathrm{g} / \mathrm{l}$. Among the test concentrations prepared from the 
preliminary toxicity test the mortality of $50 \%$ of the population after $96 \mathrm{hrs}$ exposure was observed $67.5 \mu \mathrm{g} / \mathrm{l}$ on concentration of copper.

\subsection{Changes of Total Protein}

In the haemolymph of untreated crab, the total protein was between $60.22 \pm 0.34$ to $61.99 \pm 0.58$. Exposure to copper reduced the total protein content in haemolymph which was evident after 10 days in lower concentration $(6.75 \mu \mathrm{g} / \mathrm{l})$ and after 5 days in higher concentration $(13.4 \mu \mathrm{g} / \mathrm{l})$ being $57.82 \pm 0.44$ and 56.76 \pm 0.37 respectively. The percentage of total protein reduced gradually in relation to exposure duration. After 15 days of exposure it was $54.97 \pm 0.54$ at $(6.75 \mu \mathrm{g} / \mathrm{l})$ and $53.51 \pm 0.61$ at $(13.4 \mu \mathrm{g} / \mathrm{l})$ concentrations of copper (Fig.1).

\subsection{Changes of Total Free Sugar}

In the haemolymph of untreated crab, the total free sugar was between 11.49 \pm 0.24 to $12.03 \pm 0.27$. Exposure to copper reduced the total free sugar content in haemolymph which was evident after 10 days in lower concentration $(6.75 \mu \mathrm{g} / \mathrm{l})$ and after 5 days in higher concentration $(13.4 \mu \mathrm{g} / \mathrm{l})$ being $9.93 \pm 0.30$ and $9.07 \pm 0.46$ respectively. The percentage of total free sugar reduced gradually in relation to exposure duration. After 15 days of exposure it was $7.56 \pm 0.41$ at $(6.75 \mu \mathrm{g} / \mathrm{l})$ and $7.02 \pm 0.05$ at $(13.4 \mu \mathrm{g} / \mathrm{l})$ concentrations of copper (Fig.2).

\subsection{Changes of Total lipid}

In the haemolymph of untreated crab, the total lipid was between $51.19 \pm 0.95$ to $52.31 \pm 0.60$. Exposure to copper reduced the total lipid content in haemolymph which was evident after 10 days in lower concentration $(6.75 \mu \mathrm{g} / \mathrm{l})$ and after 5 days in higher concentration $(13.4 \mu \mathrm{g} / \mathrm{l})$ being $44.71 \pm 0.55$ and $43.25 \pm 0.58$ respectively. The percentage of total lipid reduced gradually in relation to exposure duration. After 15 days of exposure it was $41.37 \pm 1.15$ at $(6.75 \mu \mathrm{g} / \mathrm{l})$ and $37.94 \underline{ \pm 0.72}$ at $(13.4 \mu \mathrm{g} / \mathrm{l})$ concentrations of copper ( Fig.3).

\section{Discussion}

In recent years, there is a growing concern worldwide on the environmental pollution due to indiscriminate use of pesticides due to their persistence, toxicity at low concentrations and bioaccumulation by biota. Biochemical changes induced by heavy metal stress is due to disturbed metabolism manifested by inhibition of enzymes, retardation of growth and reduction in the fecundity and longevity of the organism. Most of the heavy metals act as metabolic depressors and generally affect the activity of biologically active molecules such as proteins, carbohydrates and lipids [9]. The exposure of aquatic organisms to even very low 
levels of pesticides causing alterations in the nutritional value of finfish and shellfish as well as their biochemical constituents, physiological and histological functions has been widely documented $[10,11,12]$.

Oxygen consumption is one of the most important physiological phenomenona, which controls all metabolic activities. It is the most important indicator of metabolic rate and status of the stress condition of exposed animals [13]. Since cellular and sub-cellular functions form the basis of all disorders, the toxic effects of xenobiotics mainly influence the cellular responses. The injury caused to cells by foreign compounds may be direct or indirect. Direct cell injury occurs when a toxicant interacts with one or more cell components. In indirect cell injury, the effect is due to a disturbance in the microenvironment of the cell. For example, when tissues have insufficient supply of oxygen during hypoxia or anoxia, the energy metabolism is disturbed leading to damage to the cellular metabolism. The increased glycolytic activity during oxygen deficiency cannot meet the energy requirements of the cell. As a result, the energy requiring processes such as protein synthesis, and glycolytic activity during oxygen deficiency cannot meet the energy requirements of the cell. As a result, the energy requiring processes such as protein synthesis, phospholipids metabolism, and membrane transport processes are inhibited. Many investigators have demonstrated harmful effects of heavy metals on histological structure of gills of crustaceans [13,14]. Similarly, when the crabs were exposed to sublethal concentration of the same toxicant for 0 , 5, 10 and 15 days showed an elevation in the haemolymph sugar level with a maximum decrease at 15 days. Physiological processes are mostly coordinated by hormones, and changes in hormone levels are expected to occur soon after exposure to environmental stress, such as pollutants, eventually acting as endocrine disruptors [13]. Hyperglycaemia is a common stress response of many aquatic animals. In crustaceans it occurs following the involvement of the hyperglycaemic hormone $(\mathrm{cHH})$ produced in the eyestalk; $\mathrm{cHH}$ mainly regulates glucose homeostastis. It belongs to the neuropeptide family synthesized in the eyestalk by medulla terminalis x-organ, and is accumulated by and released from the sinus gland. We are in agreement with the views of earlier researchers that an elevation in the haemolymph sugar level of the fresh water crab, Paratelphusa jacqemontii can occur due to copper, which may act on the neurotransmitter acting on $\mathrm{cHH}$, a haemolymph sugar level regulating hormone [15].

\section{References}

[1] Mortimer, M.R. Pesticide and trace metal concentrations in Queensland Estuarine crabs. Marine Pollut. Bull, (2000), 41(7-12), 359-366.

[2] Verma, S.R., Tonk, I.P., Gupta, A.K. and Dakia, R.C. In vivo enzymatic alterations incertain tissues of Saccobranchus fossilis following an exposure to four toxic substances. Environ. Pollut, (1981), 26, 121-127.

[3] Abramowitz, A., Hisaw, F.L. and Papandrea, D.N. The occurrence of a diabetogenic factor in the eye stalk of crustaceans. Biol. Bull, (1994), 6: 1-5. 
[4] Fingerman, N. The endocrine mechanism of crustaceans. J. Crust. Biol, (1987), 7, 1-24.

[5] APHA, 1. Standard methods for the examination of water and waste water APHA, AWWA and WPCF, New York. (1985).

[6] Lowry, O.H., Rosenbrough, N.J., Farr, A.L. and Randall, R.J. Protein measurement with the Folin- phenol reagent. J. Biol. Chem,(1951), 193, 275275.

[7] Roe, J.H. The determination of sugar in blood and spinal fluid with anthrone reagent. J. Biol. Chem, (1955), 20, 335-343.

[8] Branes, H. and Blackstock, J. Estimation of lipids in marine animals and tissues. Detailed investigation of the sulphosvanillin method for total lipids. J. Exp. Mar. Biol. Ecol, (1973), 12, 103-118.

[9] Agrahari, S. and Gopal, K. Fluctuations of certain biochemical constituents and markers enzymes as a consequence of monocrotophos toxicity in the edible freshwater fish, Channa punctatus. Pest. Biochem. Physiol, ( 2009) 94, $5-9$.

[10] Bhavan, P.S. and Geraldine, P. Alterations in concentrations of protein, carbohydrate, glycogen, free sugar, and lipid in the prawn, Macrobrachium malcolmsonii on exposure to sublethal concentrations of endosulfan. Pestic. Biochem. Physiol, (1997), 58, 89-101.

[11] Bhavan, P.S. and Geraldine, P. Biochemical stress responses in the tissues of the prawn, Macrobrachium malcolmsonii on exposure to endosulfan, Pestic. Biochem. Physiol, (2001),70, 27-41.

[12] Bhavan, P.S. and Geraldine, P. Carbaryl-induced alterations in biochemical metabolism of the prawn, Macrobrachium malcolmsonii. J. Environ. Biol, (2002), 23, 157-162.

[13] Newell, R.C. Factors affecting the respiration of intertidal invertebrates. Am. Zool, (1973), 13, 513-528.

[14] Ramanna Rao. and Ramamurthy, M.V. Histopathological effect of sublethal mercury on the gills of fresh water field crab, Oziotelphus senex. Ind. J. Comp. Anim. Physiol, (1996), 4, 33-38.

[15] Varghese, G., Naik, P.S and Katdare, M. Respiratory response and blood sugar level of the crab, Barytelphusa cunicularis exposed to mercury, copper, and zinc. Indian J. Exp. Biol, (1992), 30, 308-312. 
Fig.1. Changes of Total protein $(\mathrm{mg} / \mathrm{ml})$ in haemolymph of Paratelphusa jacquemontii exposed to sublethal concentrations of copper

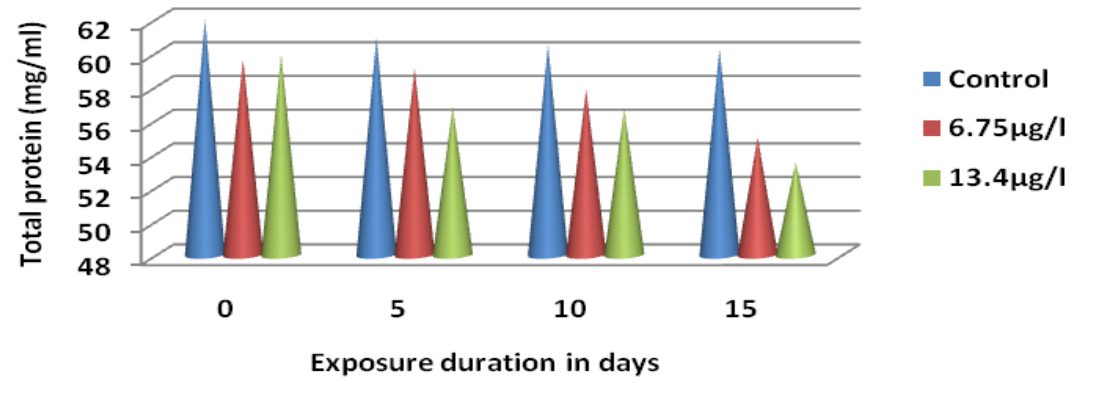

Fig.2. Changes of Total free sugar $(\mathrm{mg} / \mathrm{ml})$ in haemolymph of Paratelphusa jacqemontii exposed to sublethal concentrations of copper

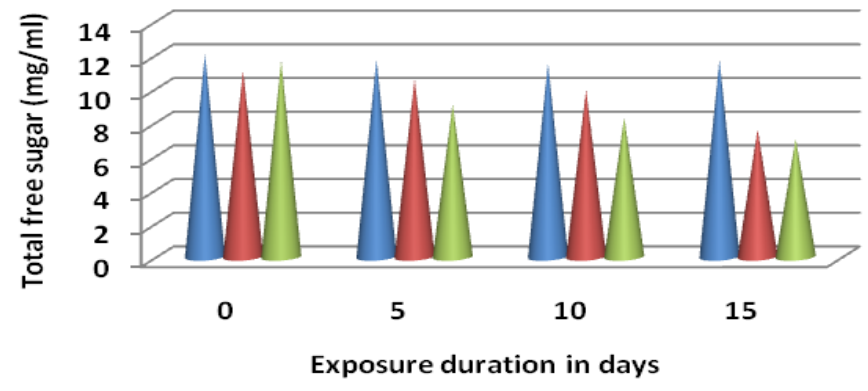

- Control

$6.75 \mu \mathrm{g} / \mathrm{l}$

$13.4 \mu \mathrm{g} / \mathrm{I}$

Fig.3. Changes of Total lipid $(\mathrm{mg} / \mathrm{ml})$ in haemolymph of Paratelphusa jacqemontii exposed to sublethal concentrations of copper

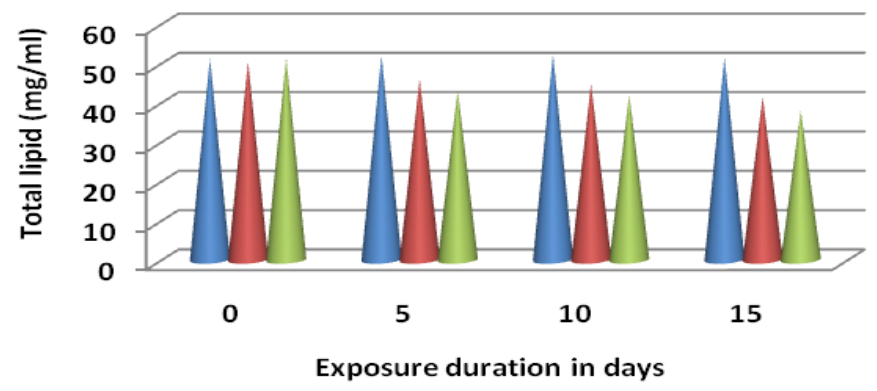

